https://doi.org/10.22319/rmcp.v12i4.5750

Nota de investigación

\title{
Ataxia enzoótica por deficiencia de cobre en ciervo rojo (Cervus elaphus) cautivo en Colima, México
}

\author{
Luis Jorge García-Márquez ${ }^{\text {a }}$ \\ Rafael Ramírez-Romero ${ }^{\text {b }}$ \\ Julio Martínez-Burnes ${ }^{c}$ \\ Alfonso López-Mayagoitia ${ }^{\mathrm{d}}$ \\ Johnatan Alberto Ruíz-Ramírez ${ }^{\text {a }}$ \\ Edgar Iván Loman-Zúñiga ${ }^{\mathrm{e}}$ \\ Fernando Constantino-Casas ${ }^{\mathrm{f}}$
}

${ }^{a}$ Universidad de Colima. Facultad de Medicina Veterinaria y Zootecnia, Av. Universidad \#333 Col. de las Víboras 28040, Colima, México.

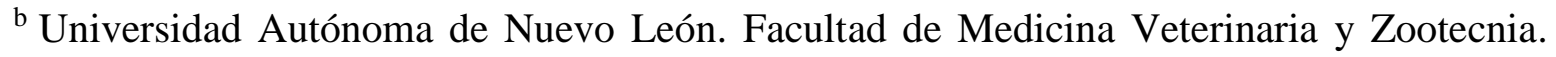
Nuevo León, México.

${ }^{c}$ Universidad Autónoma de Tamaulipas. Facultad de Medicina Veterinaria y Zootecnia. Tamaulipas, México.

${ }^{\mathrm{d}}$ University of Prince Edward Island. Atlantic Veterinary College. Charlottetown, Canadá.

${ }^{\mathrm{e}}$ Universidad Nacional Autónoma de México. Facultad de Medicina Veterinaria y Zootecnia. Ciudad de México, México.

${ }^{\mathrm{f}}$ University of Cambridge. Department of Veterinary Medicine. Cambridge, Reino Unido

*Autor de correspondencia: jruiz7@ucol.mx 


\section{Resumen:}

El objetivo del trabajo fue describir un caso de ataxia enzoótica en un Cervus elaphus (ciervo rojo) cautivo asociado a deficiencia de cobre, en el estado de Colima, México. En julio y octubre del 2018 dos hembras de ciervo rojo de 3 y 7 años manifestaron incoordinación con debilidad de los miembros posteriores y se estableció un diagnóstico anatomopatológico de ataxia progresiva. En septiembre del 2019 una hembra de 13 años manifestó signos nerviosos similares a los casos del 2018, por lo que se tomó una muestra de sangre para la medición sérica de cobre. Al animal se le aplicó eutanasia para su examen post mortem y se recolectaron muestras de tejido para histología, también se tomaron muestras de hígado, riñón, forraje y suelo para la medición de cobre y molibdeno. Las principales lesiones se encontraron microscópicamente en medula espinal, que mostró leucomalacia, desmielinización, cuerpos esferoides y cromatolisis neuronal. La concentración de cobre fue 2.7 en hígado, 4.67 en riñón y 0.08 en suero $(\mathrm{mg} / \mathrm{kg} \mathrm{MS}$ o ppm). La relación $\mathrm{Cu}$ :Mo para el suelo 1 fue $\mathrm{Cu}$ 8.48; Mo 3.00; Cu:Mo 2.83:1, suelo 2: Cu 9.10; Mo 3.00; Cu:Mo 3.03:1. Forraje 1: Cu 6.59; Mo 7.35; Cu:Mo 0.90:1; forraje 2: Cu 2.77; Mo $6.12 \pm 0.61$; $\mathrm{Cu}: \mathrm{Mo}$ 0.45:1. Los signos clínicos, lesiones microscópicas y los niveles bajos de $\mathrm{Cu}$ en suero, hígado y forrajes son consistentes con ataxia enzoótica por deficiencia primaria de cobre. Hasta donde se conoce, este es el primer informe de ataxia enzoótica en un ciervo rojo cautivo en México.

Palabras clave: Cervus elaphus, Colima, Cobre, Ataxia enzoótica, Ciervo rojo.

Recibido: 31/07/2020

Aceptado: 17/12/2020

El ciervo rojo (Cervus elaphus) es propenso a padecer enfermedades metabólicas cuando es criado en cautiverio. La deficiencia de cobre $(\mathrm{Cu})$ en esta especie ha sido asociada a osteocondrosis, ataxia enzoótica y pobre crecimiento en ciervos jóvenes ${ }^{(1-4)}$. Estos síndromes han sido reconocidos en ciervos de granjas, pero no en poblaciones silvestres. La ataxia enzoótica es una enfermedad metabólica de los cérvidos que causa parálisis lenta y progresiva afectando principalmente los miembros posteriores. Los signos clínicos son el resultado de una leucomielomalacia, o sea, necrosis de la substancia blanca de la médula espinal. Microscópicamente se caracteriza por una desmielinización de los axones de la médula espinal asociada a una deficiencia de cobre ${ }^{(5,6,7)}$. Además, puede haber cambios degenerativos en neuronas del cerebro o cerebelo, las cuales también exhiben lisis o rexis nuclear y solo en algunos casos se produce necrosis cerebrocortical con edema cerebral agudo ${ }^{(5,7)}$. La morbilidad de esta enfermedad es baja, menor al $1 \%$, aunque en algunos casos puede llegar a ser hasta del $13 \%{ }^{(8,9,10)}$. La ataxia enzoótica en cérvidos ha sido descrita en Europa y 
Nueva Zelanda, donde es considerado un problema de salud generalizado en las granjas de ciervo rojo ${ }^{(2,11,12)}$. En América se ha reportado en ciervo rojo de Argentina ${ }^{(5)}$.

En México existen 54 Unidades de Manejo, para la conservación de vida silvestre (UMAS) de Cervus elaphus y son de tipo extensivo, distribuidos en 16 estados de la República Mexicana, y Colima cuenta con una de ellas ${ }^{(13)}$. En México no se ha tenido ningún informe de ataxia enzoótica en las UMAS de ciervos rojo cautivos, por eso es importante describir por primera vez la presencia de este tipo de enfermedad. El objetivo de este trabajo fue describir los aspectos clínicos y patológicos de la ataxia enzoótica en un ciervo rojo (Cervus elaphus) cautivo y su relación con la deficiencia de cobre, en el estado de Colima, México.

La UMA "Rancho el Peregrino" (SEMARNAT-UMA-IN0013-COL/2003) está formado por 21 ciervos rojos (Cervus elaphus) (4 machos, 9 hembras y 8 crías), con edades de entre 1 mes a 15 años. Se encuentra ubicada a los $19^{\circ} 15^{\prime} \mathrm{N}$ y $103^{\circ} 43^{\prime} \mathrm{O}$ y a $490 \mathrm{msnm}$ en el municipio de Colima, México ${ }^{(14)}$. El propósito es la cría en cautiverio del C. elaphus en un sistema extensivo para la producción de carne y cornamenta dura. Se tienen destinadas 11 ha divididas en seis potreros, con pasto Cynodon nlemfuensis, árboles de Pithecellobium dulce y Acacia farneciana; además se suplementan durante todo el año con $300 \mathrm{~g}$ animal/día de maíz molido, soya, salvado de trigo, pasta de coco y harina de alfalfa adicionado con sales minerales (cada $100 \mathrm{~g}$ contiene: fosforo, calcio, hierro, magnesio, cobre, zinc, manganeso, cobalto, yodo, selenio y vitamina A). Para el manejo reproductivo, las montas se llevan a cabo de octubre a diciembre y los partos ocurren en junio y julio; como medicina preventiva, lo ciervos se desparasitan y se vacunan contra clostridiasis. Cada 21 días se asperjan con garrapaticida durante la primavera y otoño.

Durante el 2018 se presentaron dos hembras de ciervo rojo de 3 y 7 años de edad (pesos promedios de 60 y $80 \mathrm{~kg}$ respectivamente) con historia clínica de incoordinación, debilidad de los miembros pélvicos, caídas frecuentes y locomoción alterada de 3 a 18 meses de evolución; también hubo pérdida de peso progresiva y finalmente postración. El primero de estos casos sucedió en julio y el segundo en octubre del mismo año. En ambos animales solo se realizó la necropsia y estudio histopatológico cuyo diagnóstico final fue leucoencefalomalacia bilateral severa, sugerente de ataxia progresiva por deficiencia de cobre. En septiembre del 2019 otra de las hembras de la UMA manifestó signos clínicos similares a los casos observados en el 2018. Esta hembra tenía 13 años de edad y un peso promedio $95 \mathrm{Kg}$. En el examen clínico se observaron algunas laceraciones en la piel en distintas regiones del cuerpo, originadas por la postración. Se llevó a cabo un examen neurológico a distancia, donde se observó ataxia propioceptiva ligera y lentamente progresiva. Estos signos eran más evidentes cuando el animal caminaba en círculos, o al jalar la cola hacia uno de los lados. También mostró debilidad de los miembros posteriores, alteración de la ambulación (incoordinación bamboleante y miembros pélvicos entrecruzados (paso de tijera), dismetría por hipermetría, movimientos de circunducción (animal está dando 
vueltas), pérdida de la propiocepción consciente, cuello rígido y dificultad para pararse. De igual manera mostraba dificultad para levantar los tarsos, los cuales arrastraba durante la marcha; además presentaba pérdida de peso, opistótonos, extensión tónica de miembros, paraparesia, exacerbación, postración y depresión. Considerando que la historia y signos clínicos fueron similares a los casos del 2018, se tomó una muestra sanguínea para obtener suero y realizar la medición sérica de cobre. Debido a la severidad de los signos clínicos se realizó la eutanasia mediante una sobredosis intravenosa de barbitúrico $(5 \mathrm{ml} / 1.0 \mathrm{~kg}$ de peso corporal) (Pisabental ${ }^{\circledR}$ pentobarbital sódico 6.3\%, Pisa, SAGARPA, Q-7833-215, Guadalajara, Jalisco, México).

El cadáver se remitió a la sala de necropsia del laboratorio de Patología de la Facultad de Medicina Veterinaria y Zootecnia de la Universidad de Colima, para realizar el estudio post mortem. Durante la necropsia no se observaron lesiones macroscópicas evidentes, por lo que se obtuvo la médula espinal completa, y de acuerdo con la localización anatómica se dividió en las siguientes secciones: cervical craneal, cervical caudal, torácica craneal, torácica caudal, lumbar craneal, lumbar caudal, sacra craneal, sacra caudal y coccígea; así mismo se tomaron muestras de los nervios ciáticos y encéfalo. Las muestras recolectadas se fijaron en formalina al 10\% ( $\mathrm{pH} 7.2)$, se procesaron con la técnica histológica de rutina, se incluyeron en parafina y se cortaron a $6 \mu \mathrm{m}$ de grosor para teñirlas con hematoxilina y eosina (HE). También se utilizó la tinción de Luxol Fast Blue para evaluar la mielina de la médula espinal $^{(15)}$. Por otra parte, se tomaron muestras de hígado, riñón, forraje y suelo de dos potreros donde pastoreaban los ciervos, para determinar los niveles de cobre y molibdeno utilizando la técnica de espectrometría de absorción atómica ${ }^{(16,17)}$.

Los cambios macroscópicos más relevantes a la necropsia fueron: pobre condición corporal (escala 2/5), pelo hirsuto, zonas alopécicas, laceraciones cutáneas y hematomas subcutáneos; ocasionados por la postración. El hígado mostró de manera multifocal áreas discretas de fibrosis capsular. Los demás órganos no presentaron cambios macroscópicos evidentes (Figura 1). En el estudio histológico, las lesiones más relevantes se encontraron en la médula espinal, principalmente en los funículos ventrales y laterales, con menos evidencia en los funículos dorsales; estas lesiones eran bilaterales y simétricas. En la sustancia blanca se observaron extensas áreas de desmielinización, caracterizadas por la distensión notable de las vainas de mielina, las cuales en el interior mostraban escasos fragmentos hipereosinofílicos de axones y algunas células Gitter (cámaras de digestión); algunos axones se encontraban tumefactos e hipereosinofílicos (cuerpos esferoides). Mediante la tinción de Luxol Fast Blue en cada una de las secciones de la médula espinal, se evidenció la pérdida de mielina (desmielinización) en los funículos laterales y ventrales, principalmente en las zonas adyacentes a la fisura ventral medial. Las zonas afectadas se caracterizaban por la pérdida de la afinidad tintorial. En los nervios eferentes de la porción lumbar se apreciaban focos de mineralización distrófica, así como escasos cuerpos esferoides. Algunas neuronas, principalmente de las astas ventrales de la substancia gris se encontraban tumefactas, con 
pérdida de la sustancia de Nissl o con los gránulos marginados a la periferia (cromatolisis central).

Figura 1: Muestras de tejido nervioso de ciervo rojo (C. elaphus) para evaluación histopatológica

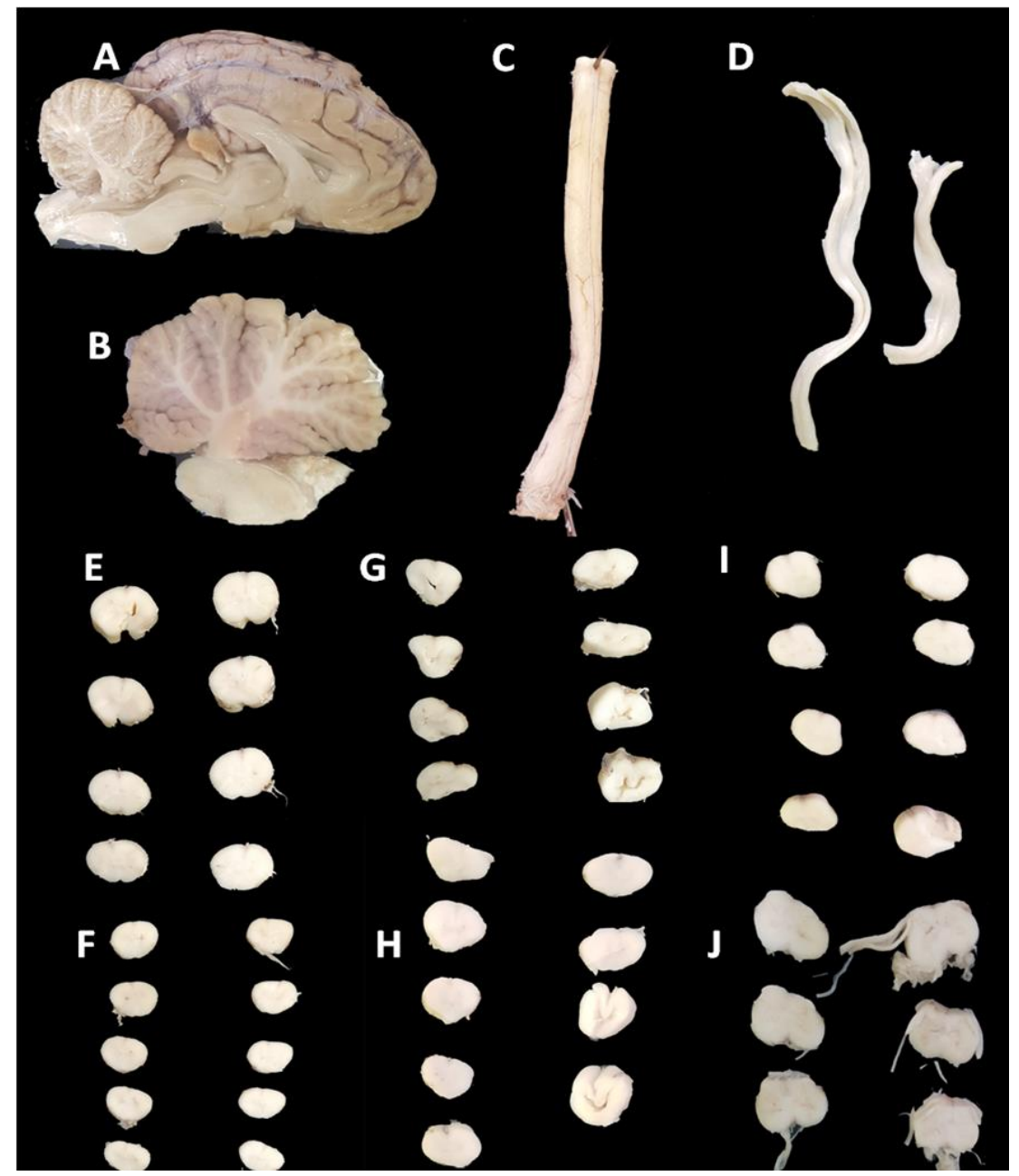

A. Encéfalo, B. Cerebelo, C. Médula espinal, D. Nervios ciáticos, E. Cervical craneal, F. Cervical caudal, G. Torácica craneal, H. Torácica caudal, I. Lumbar, J. Sacra.

Adicionalmente, por cada sección evaluada había escaso número de neuronas carentes de núcleo y su citoplasma contenía moderada cantidad de gránulos cafés ocres compatibles con lipofucsina (Figura 2). No se observó reacción inflamatoria en ninguno de los cortes de médula espinal. Histológicamente, no se observaron lesiones en encéfalo, nervio ciático, bazo, rumen, retículo, omaso, abomaso, riñones, pulmones, tráquea, glándula tiroides, páncreas y vejiga. A nivel hepático se corroboró microscópicamente la fibrosis leve localizada a nivel capsular y que se consideró sin relevancia diagnóstica. En el Cuadro 1, se muestran los valores de cobre en tejidos y suero sanguíneo, mientras que en el Cuadro 2, se muestran los valores de los microminerales de $\mathrm{Cu}$, Mo y la relación $\mathrm{Cu}$ :Mo en el forraje y suelos. 
Figura 2: Corte transversal de la porción cervical de la médula espinal, teñido con H-E

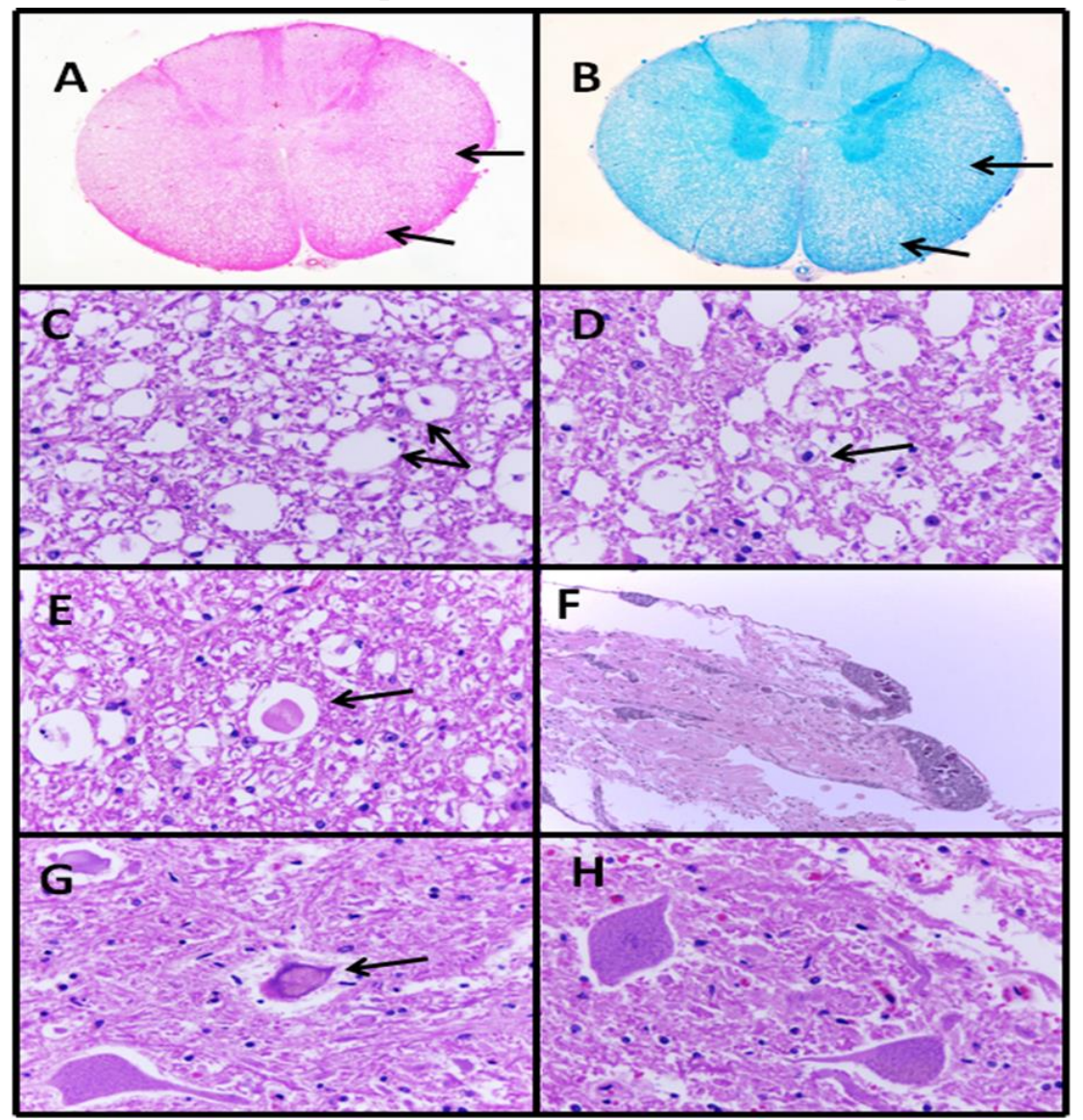

A. Los funículos ventrales y laterales se observan con áreas extensas simétricas bilaterales de desmielinización (flechas). B. Corte transversal de la porción cervical de la médula espinal teñido con Luxol fast blue, se hacen evidentes las áreas de desmielinización con la pérdida de la afinidad tintorial (flechas). C. Porción cervical craneal de la médula espinal, las vainas de mielina están dilatadas y en su interior se aprecian fragmentos de axones y la desmielinización (flechas). D. Cámaras de digestión, en su interior hay una célula Gitter (flecha) y restos de un axón. E. Cuerpos esferoides (flecha). F. Zonas de mineralización en los nervios eferentes de la asta dorsal de la porción dorsal de la médula espinal. G. Cromatolisis central en una neurona y pérdida de núcleos (flecha). H. Pigmento café ocre granular en un soma neuronal compatible con lipofucsina.

Cuadro 1: Valores de cobre (mg/kg MS o ppm) en tejidos y suero sanguíneo de ciervo rojo (Cervus elaphus) en cautiverio

\begin{tabular}{ccc}
\hline Muestra & $\mathbf{C u}$ & $\mathbf{C u}$, Referencia \\
\hline Suero & 0.08 & $0.5-1.5$ \\
Hígado & 2.70 & $6.4-29$ \\
Riñón & 4.67 & $3.3-7.2$ \\
\hline
\end{tabular}

Valores de referencia tomados de: ${ }^{(7,12,18)}$. 
Cuadro 2: Valores de cobre, molibdeno y la relación Cu:Mo (mg/kg MS o ppm) en suelo y forraje de dos praderas de la UMA El Peregrino

\begin{tabular}{cclllcc}
\hline Muestra & Cu (ppm) & $\begin{array}{l}\text { Referencia } \\
\text { Cu }\end{array}$ & $\begin{array}{l}\text { Mo } \\
(\mathbf{p p m})\end{array}$ & $\begin{array}{l}\text { Referencia } \\
\text { Mo }\end{array}$ & $\begin{array}{l}\text { Cu:Mo } \\
1-5\end{array}$ & $\begin{array}{l}\text { Referencia } \\
\text { Cu:Mo }\end{array}$ \\
Suelo 1 & $8.48 \pm 0.45$ & $\begin{array}{l}5.1-10 \\
(\dot{\mathrm{X}}=7.5)\end{array}$ & $3.00 \pm 0.30$ & $\begin{array}{l}1-5 \\
(\dot{\mathrm{X}}=3.0)\end{array}$ & $2.83: 1$ & $2: 1$ \\
Suelo 2 & $9.10 \pm 0.48$ & $\begin{array}{l}5.1-10 \\
(\dot{\mathrm{X}}=7.5)\end{array}$ & $3.00 \pm 0.30$ & $\begin{array}{l}1-5 \\
(\dot{\mathrm{X}}=3.0)\end{array}$ & $3.03: 1$ & $2: 1$ \\
Forraje 1 & $6.59 \pm 0.35$ & $\begin{array}{l}8-11 \\
(\dot{\mathrm{X}}=9.5)\end{array}$ & $7.35 \pm 0.74$ & $\begin{array}{l}0.07-5.0 \\
(\dot{\mathrm{X}}=2.5)\end{array}$ & $0.90: 1$ & $2: 1$ \\
Forraje 2 & $2.77 \pm 0.15$ & $\begin{array}{l}8-11 \\
(\dot{\mathrm{X}}=9.5)\end{array}$ & $6.12 \pm 0.61$ & $\begin{array}{l}0.07-5.0 \\
(\dot{\mathrm{X}}=2.5)\end{array}$ & $0.45: 1$ & $2: 1$ \\
\hline
\end{tabular}

La ataxia enzoótica es una enfermedad neurodegenerativa ocasionada por la deficiencia de cobre ya sea primaria o secundaria. La deficiencia primaria o absoluta ocurre cuando los forrajes o suelo son pobres en este elemento, y por lo tanto hay una ingesta insuficiente, mientras tanto la secundaria o condicionada, es provocada por una reducción en su absorción a nivel intestino, generando bajas disponibilidades para los tejidos ${ }^{(6,7,12)}$. Esta enfermedad afecta principalmente ovinos, aunque también ha sido descrita en caprinos, lechones y ciervo rojo $^{(5)}$. Su diagnóstico se lleva a cabo a través de signos clínicos, lesiones microscópicas en el sistema nervioso central y la determinación de niveles de cobre en el hígado ${ }^{(12)}$. En algunos informes se refiere que la morbilidad de ataxia enzoótica en ciervo rojo y en híbridos Wapiti rojos es alrededor del $1 \%$, aunque puede llegar hasta el $13 \%(5,10)$; sin embargo, dichas proporciones podrían variar dependiendo de la región geográfica, además, el suministro adecuado con suplementos de $\mathrm{Cu}$ a los animales puede prevenir eficazmente la enfermedad, mientras que el tratamiento de los animales afectados produce cierta remisión de los signos sin eliminar la enfermedad, por lo que la ataxia generalmente progresa hasta la muerte de los animales $^{(7,8)}$. En la UMA "El Peregrino" la morbilidad fue del $9.8 \%$ y $0.1 \%$ de mortalidad, manteniéndose dentro del rango establecido según la literatura ${ }^{(8,9,10)}$. Las causas más comunes de morbilidad y mortalidad en ciervo rojo cautivo en la UMA "El Peregrino" han sido: $33.4 \%$ babesiosis transmitida por la garrapata del género Rhipicephalus, $17.7 \%$ poliartritis secundaria a una onfaloflebitis, $13.7 \%$ bronconeumonía supurativa, $9.8 \%$ ataxia enzoótica, $7.8 \%$ fracturas por traumatismo, $3.9 \%$ diarrea y timpanismo, $2.0 \%$ de endoparásitos Fasciola hepatica y Oesophagostomum spp $^{(22)}$.

La signología clínica de ataxia enzoótica en ciervos, se presentó con incoordinación y debilitamiento de los miembros pélvicos, la cual fue progresiva y finalmente culminó con la postración del animal. Estos signos concuerdan perfectamente con los observados por otros autores ${ }^{(10,11,12)}$. Las lesiones en la médula espinal en la ataxia enzoótica son puramente microscópicas, y esto explica por qué no se observaron lesiones a la necropsia. La 
distribución de la leucomielomalacia, afectando principalmente los funículos laterales y ventrales adyacente a la fisura ventral media fueron también consistentes con otros reportes en la literatura ${ }^{(5,7,12)}$. Microscópicamente los hallazgos observados fueron bilaterales y simétricos en la substancia blanca de la médula espinal con degeneración walleriana, desmielinización, escasos cuerpos esferoides, así como células Gitter; en las neuronas, de las astas ventrales suele observarse cromatolisis central y necrosis neuronal ${ }^{(23,24,25)}$. La patogenia de esta enfermedad no se encuentra del todo esclarecida, sin embargo, se sabe que los bajos niveles de cobre en el organismo interfieren con el adecuado funcionamiento de diversas enzimas, entre ellas el superóxido dismutasa, ceruloplasmina y la citocromooxidasa, lo que ocasiona la supresión de la respiración mitocondrial y por ende la disminución en la producción de fosfolípidos y la mielina ${ }^{(26,27)}$. A esto se suma la acción de radicales libres ocasionando una axonopatía desmielinizante. En otras palabras, las lesiones son típicas de una enfermedad neurodegenerativa en ciervos ${ }^{(5,26,27)}$.

Los valores de cobre en suero sanguíneo e hígado, se encontraron por debajo de los valores considerados como límites normales (para suero sanguíneo de 0.5 a $1.5 \mathrm{mg} / \mathrm{kg}$ y de $50 \mathrm{ppm}$ en materia seca para hígado). Sin embargo, se han descrito casos de ataxia enzoótica, donde se manifiesta por debajo de $25 \mathrm{ppm}$ e inferiores a $15 \mathrm{ppm}^{(28,29,30)}$. En el presente estudio se encontraron muy por debajo de estos límites, a pesar de que el organismo es muy eficiente en mantener los niveles de cobre en sangre entre los valores óptimos, estas características también han sido observadas y registradas por otros autores ${ }^{(28,29,31,32)}$. El hígado tiene la capacidad de ocasionar la redistribución del $\mathrm{Cu}$ y posteriormente favorecer su acumulación en riñón para después ser excretados en la orina ${ }^{(26)}$, esto genera que los niveles dentro del tejido renal, como en este caso $(4.67 \mathrm{mg} / \mathrm{kg})$, no se vean afectados y sean encontrados dentro del rango establecido (3.3 a $7.2 \mathrm{mg} / \mathrm{kg})$.

El análisis de cobre y molibdeno realizados en los pastos y en el suelo, así como su relación $\mathrm{Cu}$ :Mo sugiere una baja de cobre en el pasto, lo cual se correlaciona con los niveles bajos de cobre encontrados en hígado y suero sanguíneo de los ciervos, siendo esto indicativo de una deficiencia primaria. Sin embargo, se debe considerar que la enfermedad se presenta durante todo el año, pero puede ser estacional, debido a la variación de los requerimientos nutricionales de los animales durante el año y las diferencias en la composición mineral del suelo y pastos, según la estación del año; disminuyendo en invierno-primavera e incrementándose en el verano-otoño como lo mencionan otros autores ${ }^{(19,20,21)}$. En ciervos de granja, las concentraciones de $\mathrm{Cu}$ en el hígado $<4 \mu \mathrm{g} / \mathrm{kg}$ y las concentraciones séricas $<0.3$ $\mu \mathrm{g} / \mathrm{ml}$ indican deficiencia de este elemento. Se considera como deficiencia de $\mathrm{Cu}$ en forrajes $<10$ ppm y $<3$ ppm de molibdeno, perdiéndose la relación de Cu:Mo de 2:1 ${ }^{(6)}$, como en el presente estudio 0.90:1 y 0.45:1. Esto sugiere que el molibdeno no interfirió en el metabolismo del $\mathrm{Cu}$ en estos ciervos. Se consideran que para el hígado, concentraciones de $\mathrm{Cu}>6.35 \mathrm{mg} / \mathrm{kg}$ se consideran adecuados y $<3.81 \mathrm{mg} / \mathrm{kg}$ de tejido representa el rango de deficiente. Para las concentraciones séricas de $\mathrm{Cu}$, los rangos de $<0.32 \mathrm{mg} / \mathrm{L}$ son de 
deficiencia $y>0.51$ son adecuados ${ }^{(2)}$. En deficiencias severas de cobre se han reportado

problemas óseos y articulares, como osteocondrosis y fracturas espontáneas ${ }^{(1,7,28)}$, sin embargo, esto no fue evidente en los ciervos de la UMA de Colima.

Los hallazgos clínicos, de necropsia e histopatología junto con el análisis de Cu y Molibdeno fueron utilizados para hacer el diagnóstico final de leucomielomalacia bilateral o ataxia enzoótica por deficiencia de cobre. Esta enfermedad nutricional de la UMA en Colima fue clasificada como una deficiencia de cobre primaria o absoluta, debido a los bajos niveles de $\mathrm{Cu}$ en el forraje, mismos que fueron insuficientes para cubrir los requerimientos nutricionales de los animales, reflejando niveles bajos de Cu en hígado, suero y favoreciendo al desarrollo de lesiones degenerativas progresivas en el sistema nervioso central. Aunque los niveles de $\mathrm{Cu}$ no fueron analizados en los casos presentados en el 2018, la signología y lesiones anatomopatológicas fueron sugerentes de ataxia enzoótica; sin embargo, es importante que ante la manifestación de signos neurológicos en ciervos estabulados se considere a esta enfermedad como diagnóstico diferencial, y que de manera adicional al estudio clínicopatológico, se lleve a cabo la medición de $\mathrm{Cu}$ y Mo (suero, hígado, forraje y suelo) para realizar un diagnóstico definitivo y poder establecer medidas de prevención. Con base en la búsqueda bibliográfica, se considera que este es el primer informe de ataxia enzoótica en un ciervo rojo cautivo en México.

\section{Agradecimientos}

Este Proyecto fue financiado por la Red Académica de Enfermedades en la Vida Silvestre y su impacto como reservorio (PROMEP-CA-SEP). Se agradece a Alfredo Díaz por el procesamiento histológico de las muestras en el Departamento de Aves de la Facultad de Medicina Veterinaria y Zootecnia de la Universidad Nacional Autónoma de México.

\section{Literatura citada:}

1. Wilson PR, Grace ND. A review of tissue reference valves used to assess the trace element status of farmed red deer (Cervus elaphus). NZ Vet J 2001;49(4):126-132.

2. Grace ND, Wilson PR. Trace element metabolism dietary requirements, diagnosis and prevention of deficiencies in deer. NZ Vet J 2002;50(6):252-259.

3. Grace ND, Wilson PR, Quinn AK. The effect of copper-amended fertilizer and copper oxide wire particles on the copper status of farmed red deer (Cervus elaphus) end their progeny. NZ Vet J 2005;53(1):31-38.

4. Grace ND, Wilson PR, Quinn AK. Impact of molybdenum on the copper status of red deer (Cervus elaphus). N Z Vet J 2005;53(2):137-141. 
5. Soler JP, Cseh SB. Ataxia enzoótica en ciervo rojo (Cervus elaphus) en Argentina. Arch Med Vet 2007;39(1):73-76.

6. Handeland K, Bernhoft A, Aartun MS. Copper deficiency and effects of copper supplementation in a herd of red deer (Cervus elaphus). Acta Vet Scand 2008;50:1-8.

7. Maryam R, Ghulam M. Copper deficiency in ruminants in Pakistan. Matrix Sci Med (MSM) 2018; 2(1):18-21.

8. Booth DH, Wilson PR, Alexander AM. The effect of oral copper wire on liver copper in farmed red deer. NZ Vet J 1989;37:98-101.

9. Jones DG. Trace element deficiencies. In: Alexander TL, Buxton D, editor. Management and diseases of deer. 2. Midlothian, Scotland: Macdonald Lindsay Pindar; 1994;182191.

10. Thompson KG, Audigé L, Arthur DG, Julian AF, Orr MB, McSporran KD, Wilson PR. Osteochondrosis associated with copper deficiency in young farmed red deer and wapitired deer hybrids. NZ Vet J New 1994;42:137-143.

11. Audigé L, Wilson PR, Morris RS, Davidson GW. Osteochondrosis skeletal abnormalities and enzootic ataxia associated with copper deficiency in a farmed red deer (Cervus elaphus). NZ Vet J 1995;43:70-76.

12. Vengust G, Svara T, Gombac M, Zele D. Enzootic ataxia associated with copper deficiency in a farmed red deer: a case report. Vet Med-Czech 2015;60(9):522-526.

13. Álvarez RJ, Medellín RA. Cervus elaphus Linnaeus, (1758). Vertebrados superiores exóticos en México: diversidad, distribución y efectos potenciales. Instituto de Ecología, Universidad Nacional Autónoma de México. Bases de datos SNIB-CONABIO. Proyecto U020. México, D.F. 2005.

14. INEGI. Instituto Nacional de Estadística, Geografía e Informática. Marco Geoestadístico: aspectos geográficos de Colima; 2019.

15. Prophet EB, Mills B, Arrington JB, Sobin LH. Métodos histotecnológicos. Instituto de Patología de las Fuerzas Armadas de los Estados Unidos de América (AFIP) Registro de Patología de los Estados Unidos de América (ARP) Washington, D.C. 1995;280.

16. Perkin Elmer. Analytical methods for atomic absortion spectrophotometry. Connecticut, USA: Ed Perkin Elmer Corporation; 1982. 
17. NOM. Norma Oficial Mexicana NOM-010-ZOO-1994. Determinación de cobre, plomo y cadmio en hígado, músculo y riñón de bovinos, equinos, porcinos, ovinos y aves, por espectrometría de absorción atómica. SAGARPA. SENASICA. Diario Oficial Mexicano, 9 de enero 1995;16-25.

18. Falandysz J, Szymczyk KK, Brzostowski A, Zalewski K, Zasadowski A. Concentrations of heavy metals in the tissues of red deer (Cervus elaphus) from the region of Warmia and Mazury, Poland. Food Addit Contam 2005;22:141-149.

19. Cabrera TE, Sosa REE, Castellanos RAF, Gutiérrez BAO, Ramírez SJH. Comparación de la concentración mineral en forrajes y suelos de zonas ganaderas del estado de Quintana Roo, México. Vet Mex 2009;40:167-17.

20. De La Vega VJA. Perfil mineral en un hato de vacas en ordeña, en los períodos de seca y lluvias: relación con variables hemáticas [Tesis licenciatura]. Facultad de Medicina Veterinaria y Zootecnia. Universidad Veracruzana, México. 2009.

21. NCR. National Research Council. Nutrient Requirements of Small Ruminants: Sheep, Goats, Cervids, and New World Camelids. Washington, DC, USA: The National Academies Press; 2007. https://doi.org/10.17226/11654.

22. Anzar DA. Estudio retrospectivo de causas de mortalidad del ciervo rojo (Cervus elaphus) cautivo en el rancho "El Peregrino" del Estado de Colima, México [Tesis licenciatura]. Facultad de Medicina Veterinaria y Zootecnia de la Universidad de Colima; 2011.

23. Hartman HA, Evenson MA. Deficiency of cooper can cause neuronal degeneration. Med Hypotheses 1992;38:75-78.

24. Yoshikawa HH, Seo T, Oyamada T, Ogasawara T, Oyamada T, Yoshikawa X, Wei S, Wang A, Li Y. Histopathology of enzootic ataxia in Sika deer (Cervus nippon temminck). J Vet Med Sci 1996;58(9):849-854.

25. Geisel O, Betzl E, Dahme E, Schmahl W, Hermanns W. Enzootic spinal ataxia in fallow and wild red deer in Upper Bavaria. Tierarztl Prax Ausg G Grosstiere Nutztiere. 1997;25(6):598-604.

26. Quiroz G, Bouda J. Fisiopatología de las deficiencias de cobre en rumiantes y su diagnóstico. Vet Mex 2001;32(4):289-296.

27. Cantile C, Youssef S. Nervous system. Vol 1. Maxie, M. Grant. Jubb, Kennedy, and Palmers. Pathology of domestic animals. Elsevier; 2016.

28. Mackintosh GG. Deer health and diseases. Acta Vet Hung 1998;46:381-394. 
29. Wilson PR. Bodyweight and serum copper concentrations of farmed red deer stags following oral copper oxide wire administration. NZ Vet J 1989;37:94-97.

30. Padilla S, Bouda J, Quiroz RG, Dávalos JL, Sánchez A. Biochemical and haematological vales in venous blood of captive red deer (Cervus elaphus) at high altitude. Acta Vet Brno 2000;69:327-331.

31. Ellison RS. Major trace elements limiting livestock performance in New Zealand. NZ Vet J 2002;50(3):35-40.

32. Vikoren T, Bernhof A, Waaler T, Handeland K. Liver concentrations of copper, cobalt and selenium in wild Norwegican red deer (Cervus elaphus). J Wildl Dis 2005; 41(3):569-579. 